\title{
К ВОПРОСУ О ЗАЩИТЕ ПРАВ ГРАЖДАН В СФЕРЕ ОБЕСПЕЧЕНИЯ ТРАНСПОРТНОЙ БЕЗОПАСНОСТИ ФЕДЕРАЛЬНЫМИ ОРГАНАМИ ИСПОЛНИТЕЛЬНОЙ ВЛАСТИ
}

\begin{abstract}
Аннотация: В статье рассматриваются правовые и организационные основы обеспечения транспортной безопасности, как составной части общественной безопасности, обращается внимание на административно-правовые средства обеспечения транспортной безопасности, в частности, на такие, как лицензирование, контроль, административная ответственность. По итогам рассмотрения средств обеспечения авиационной безопасности, в статье фор-мулируются ряд предложений, которые направлены на совершенствование законодательства о транспортной безопасности. Также в статье обращается внимание на деятельность федеральных органов исполнительной власти, в компетенции которых находится управление транспортным комплексом и транспортной инфраструктурой нашей страны. На основании такого рас-смотрения также вносится предложения по совершенствованию управления в рассматриваемой сфере. Методологическую основу статьи составили современные достижения теории познания. В процессе исследования применялись общефилософский, теоретический, эмпирический методы (диалектика, системный метод, анализ, синтез, аналогия, дедукиия, наблюдение, моделирование), традиционно правовые методы (формально-логический), методы, используемые в конкретно-социологических Вопросы безопасности личности, общества и государства всегда находились в центре внимания государства и гражданского общества. Глобализаџия экономики, террористические угрозы, а также нестабильная финансовая и политическая ситуачия во многих государствах заставляют по иному взглянуть на вопросы глобальной безопасности, в том числе и в сфере функиионирования транспорта, работа которого в сложившихся условиях носит достаточно уязвимый характер. Перечисленные, а также ряд других обстоятельств обусловливают акту-альность обозначенной проблемы, а также они ярко свидетельствуют о том, что вопрос административно-правового регулирования деятельности феде-ральных органов исполнительной власти в сфере обеспечения безопасности на объектах транспорта и транспортной инфраструктуры, превращен в по-следние годы в одну из важнейших управленских проблем.
\end{abstract}

Abstract: The article concerns legal and organizational fundamentals of transportation guarantees, as an element of public security. Attention is paid to administrative legal means of guaranteeing transportation security, such as licensing, control, administrative responsibility. As a result of evaluation of the means of guaranteeing aviation security, the author formulates a number of proposals for the improvement of legislation on transportation security. The article also pays attention to the activities of the federal executive bodies, whose competence includes transportation complex and transportation infrastructure of our state. Based upon such evaluation, the author also introduces proposals for improvement of administration in this sphere. The methodological basis for the article was formed with the modern achievement of cognitive theory. The process of studies involved general philosophical, theoretical, empiric methods (dialectic, systemic method, analysis, synthesis, analogy, deduction, observation, modeling), traditional legal methods (formal logic), specific sociological methods. The issues of security of a person, society and state have always been at the center of attention of both the state and the civil society. Economic globalization, terrorist threats and financial and economic instabilities in many states require that we take another view of global security issues, including those of transportation functioning, since its current work is rather vulnerable in the current situation. The said matters, as well as a number of other issues make this problem topical, and they vividly show that the issue of administrative legal regulation of the activities of federal executive bodies in the sphere of transportation security guarantee at the transportation and transportation infrastructure objects are among the most important current administrative problems. 
Ключевые слова: Транспорт, безопасность, права, человек, риск, угроза, власть, полиция, противодействие, уязвимость. Keywords: Transportation, security, rights, human, risk, threat, power, police, counteraction, vulnerability.

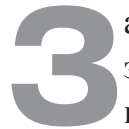
ащита прав и свобод граждан - первостепенная задача государства. Усилия по обеспечению защиты этих прав предпринимаются различными органами государственной власти и управления по самому широкому спектру направлений, одним из которых является транспортная инфраструктура нашей страны.

Известно, что транспорт и транспортная инфраструктура играют важную роль в социально-экономическом развитии страны. Обусловлено это тем, что с помощью различных видов транспорта ежедневно на десятки тысяч километров перемещается большое количество людей и товарно-материальных ценностей. С каждым годом увеличивается подвижность населения Российской Федерации - к 2016 г. она возрастет на 23 \% и составит 8,5 тыс км. на 1 жителя. В 2012 г. экспорт российских транспортных услуг вырос на 14 \% и составил 17,3 млд долл. В этом же году российскими авиакомпаниями перевезено 74 млн пассажиров, перевалка грузов в морских портах выросла на $6 \%$ и составила около 570 млн тонн, объем перевозок грузов на внутреннем водном транспорте вырос на $12 \%$ и составил 140,8 млн тонн. В городах России большое внимание уделяется развитию скоростных видов пассажирского транспорта, объем перевозок метрополитеном увеличился в 2012 г. почти на $3 \%$ и достиг 3,5 млд пассажиров. По данным Госавтоинспекции МВД России, в стране зарегистрировано 5,5 млн грузовых автомобилей, в том числе 300 тыс. автомобилей предназначенных для перевозки опасных грузов, более 900 тыс. автобусов, из которых 320 тыс. для эксплуатации подлежат лицензированию. Все эти цифры свидетельствуют о необходимости усиления мер безопасности, как на пассажирском, так и на грузовом транспорте.-

В современный период развитие транспорта и транспортной инфраструктуры выдвигает новые задачи для формирования комплексной системы транспортной безопасности. Так, в 2012 г. аварийность на автомобильном транспорте выросла на $10 \%$, на воздушном и водном транспорте на 3,4 \%, железнодорожном на 5,6 \%. Ежегодно в результате транспортных катастроф в Российской Федерации погибает около 100 тыс. людей. Все эти данные свидетельствуют, в том числе и о необходимости совершенствования административно-правового регулирования деятельности федеральных органов исполнительной власти в сфере обеспечения безопасности на транспорте и объектах транспортной инфраструктуры ${ }^{1}$.

\footnotetext{
${ }^{1}$ http://www.mintrans.ru/ (дата обращения 18.03.2013).
}

Вопросы безопасности личности, общества и государства всегда находились в центре внимания государства и гражданского общества. Глобализация экономики, террористические угрозы, а также нестабильная финансовая и политическая ситуация во многих государствах заставляют по иному взглянуть на вопросы глобальной безопасности, в том числе и в сфере функционирования транспорта, работа которого в сложившихся условиях носит достаточно уязвимый характер.

Перечисленные, а также ряд других обстоятельств обусловливают актуальность обозначенной проблемы, а также они ярко свидетельствуют о том, что вопрос административно-правового регулирования деятельности федеральных органов исполнительной власти в сфере обеспечения безопасности на объектах транспорта и транспортной инфраструктуры, превращен в последние годы в одну из важнейших управленских проблем. От решения обозначенной задачи зависит как социальноэкономическое развитие страны, так и благополучие большого количества людей, использующих для своего передвижения различные виды транспорта.

Все это диктует необходимость изучения институциональных административно-правовых средств, направленных на обеспечение безопасности на объектах транспорта и транспортной инфраструктуры, а также защиты прав граждан использующих различные виды транспорта.

Проблемы обеспечения безопасности вообще и в сфере функционирования транспорта и транспортной инфраструктуры в частности, носят достаточно актуальный характер. Без работы транспорта невозможно представить жизнедеятельность людей, функционирование хозяйствующих субъектов, помимо этого, транспортная система обеспечивает занятость миллионов граждан, транспортный комплекс является одним из основных налогоплательщиков. В этой связи вопросы безопасности в сфере функционирования транспорта касаются практически каждого человека.

Несмотря на важнейшее значение различных видов транспорта в экономике и жизни людей, обеспечение безопасности при его эксплуатации оставляет желать лучшего. К сожалению, транспорт - это не только инфраструктура, которая двигает экономику, способствует мобильности в передвижении людей, это еще и источник повышенной общественной опасности, а также объект для преступного посягательства, а в некоторых случаях и объект для террористической атаки. 
DOI: 10.7256/1811-9018.2014.8.11549

При цитировании этой статьи сноска на доі обязательна

\section{Право и политика $8(176) \cdot 2014$}

Названные и ряд других обстоятельств вызывают объективную необходимость создания дополнительных административно-правовых средств обеспечения транспортной безопасности, а также совершенствования статуса субъектов, которые будут их реализовывать.

Говоря о транспортной безопасности и безопасности транспортной инфраструктуры, необходимо отметить, что это весьма специфичные виды общественной безопасности, угрозы которым напрямую связаны с подрывом основ национальной безопасности. Исходя из этого, под транспортной безопасностью понимается состояние защищенности транспорта и транспортной инфраструктуры, потребителей транспортных услуг (пассажиров) от различного рода угроз (природного и техногенного характера), а также актов незаконного вмешательства в деятельность различных видов транспорта. В отличие от имеющихся определений, в представленном определении комплексно определен объект транспортной безопасности.

Обеспечение федеральными органами исполнительной власти безопасности на объектах транспорта и транспортной инфраструктуры напрямую связано по своему содержанию с обеспечением национальной безопасности. К сожалению, это положение не находит своего закрепления в действующем законодательстве, регулирующем вопросы национальной, общественной и транспортной безопасности. В этой связи было бы целесообразно в Стратегии национальной безопасности Российской Федерации особо подчеркнуть, что обеспечение транспортной безопасности напрямую связано с обеспечением национальной безопасности.

Раскрытие содержания обеспечения безопасности на объектах транспорта и транспортной инфраструктуры позволяет сделать вывод о том, что в этом процессе используются различные средства и инструментарий. Связано это с тем, что транспорт, это прежде всего техника, и для обеспечения транспортной безопасности техническая и технологическая составляющие играют далеко не последнюю роль. Многие аварии и транспортные катастрофы происходят из-за технических неисправностей, технологической отсталости, некачественной и устаревшей транспортной инфраструктуры и др. Однако технологические проблемы в сфере транспорта логически связаны и с правовым регулированием всех без исключения общественных отношений в сфере работы транспорта.

В этой связи представляется верным тезис о том, что нарушение технических норм, регламентов, гостов и т.п. при эксплуатации различных видов транспорта, всегда влечет за собой и нарушение юридических норм, а если быть точным - норм административного права. Исходя из этого, можно сделать вывод о том, что деятельность по обеспечению транспортной безопасности и безопасности транспортной инфраструктуры находится под режимом административно-правового воздействия, степень жесткости которого зависит от вида транспорта, рисков транспортных угроз, случаев несанкционированного вмешательства в работу соответствующего транспорта или объекта транспортной инфраструктуры. Также нормами административного права определен статус федеральных органов исполнительной власти, осуществляющих управление как в целом транспортным комплексом, так и вопросами обеспечения транспортной безопасности. Кроме того, данными нормами определяются формы и методы обеспечения соответствующего вида безопасности, а также порядок применения мер административной ответственности за нарушения транспортного законодательства².

Несмотря на проблемы децентрализации в управлении транспортным комплексом, создание большого количества авиакомпаний, акционерных транспортных предприятий, изменения в режиме хозяйствования при эксплуатации водного и железнодорожного транспорта, федеральные органы исполнительной власти не утратили своего регулирующего воздействия в транспортном комплексе нашей страны. В компетенции государства находится основной ресурс управления транспортом, а также наиболее важные вопросы в сфере обеспечения безопасности на объектах транспорта и транспортной инфраструктуры. Сейчас ни у кого не вызывает сомнения тезис о том, что только лишь хозяйствующий субъект транспортная компания не в состоянии самостоятельно решить весь комплекс вопросов в сфере обеспечения транспортной безопасности, а также выполнить при этом запросы потребителей транспортных услуг ${ }^{3}$.

За последние годы в транспортном комплексе нашей страны произошли кардинальные изменения, далеко не все из которых повысили качество транспортных услуг, а также способствовали повышению уровня безопасности на различных видах транспорта. Регулярно российское общество потрясает массовая гибель людей на воздушном, водном, автомобильном,

\footnotetext{
${ }^{2}$ См.: Куракин А.В., Трофимов О.Е. Административно-правовое регулирование обеспечения безопасности авиации и объектов авиационной инфраструктуры в зарубежных государствах // Полицейская деятельность. - 2013. - № 3. - С. 276.

${ }^{3}$ См.: Куракин А.В., Трофимов О.Е. Административно-правовое регулирование обеспечения безопасности авиации и объектов авиационной инфраструктуры в зарубежных государствах // Полицейская деятельность. - 2013. - № 3. - С.402.
} 
а также на железнодорожном транспорте. Транспортные катастрофы процесс отчасти объективный, но как показывают расследования транспортных происшествий, во многих случаях происходящий из-за пренебрежения требованиями эксплуатации соответствующего вида транспорта. Хозяйствующий субъект нередко в ущерб здравому смыслу оптимизирует свои расходы на транспортную безопасность, замену изношенного оборудования, оплату труда соответствующим специалистам и др. Все это создает дополнительные риски для жизни и здоровья пассажиров, гибели перевозимых товарно-материальных ценностей, а в конечном итоге делает российский транспорт неконкурентоспособным как на внутреннем, так и на внешнем рынке транспортных услуг.

В сложившейся ситуации в сфере обеспечения транспортной безопасности, свою долю неэффективности имеют и федеральные органы исполнительной власти как общей, так и специальной компетенции, которые, например, вовремя не осуществили контрольно-надзорное мероприятие или провели его не качественно, не проконтролировали исполнения со стороны транспортного предприятия, вынесенного в отношении его предписания или постановления. На сегодняшний день в системе управления транспортным комплексом только на федеральном уровне создано пять федеральных органов исполнительной власти, занимающихся непосредственно вопросами управления транспортным комплексом. Кроме того, вопросы транспортной безопасности находятся в компетенции МВД, ФСБ, прокуратуры.

Особенности функционирования транспорта вызывают объективную необходимость изучения зарубежного опыта обеспечения транспортной безопасности и определение возможности использования его компонентов в российских условиях. Следует отметить, что проблемы транспортной безопасности весьма актуальны для многих зарубежных государств. Во многих государствах транспорт и транспортная инфраструктура не раз подвергались несанкционированному вмешательству или террористическим атакам. Все индустриально развитые государства имеют современный транспорт и сопутствующую ему инфраструктуру, все государства для ее защиты от несанкционированного вмешательства прилагают максимум усилий. Ряду государств удалось создать транспортные компании, услугами которых пользуются во всем мире миллионы людей и тысячи хозяйствующих субъектов ${ }^{4}$.

\footnotetext{
${ }^{4}$ См.: Куракин А.В., Трофимов О.Е. Административноправовое регулирование обеспечения безопасности авиации
} и объектов авиационной инфраструктуры в зарубежных
Авторитет соответствующих зарубежных авиационных предприятий, а также предприятий, занимающихся перевозкой грузов морским и автомобильным транспортом обеспечен многолетним опытом их бесперебойной работы, а также высоким уровнем их транспортной безопасности. Современный транспорт - это высокотехнологичная отрасль экономики, которая системно требует новых технологических, информационных разработок, а также высококвалифицированных кадров. По этому аспекту российский транспортный комплекс весьма существенно отстает от целого ряда зарубежных стран. Обращает на себя внимание и логическая взаимосвязь различных видов транспорта, которая сформирована в таких государствах, как США, Германия, Япония, Великобритания, Китай. Связь различных видов транспорта между собой, делают транспортную систему замкнутой и, тем самым, более удобной и мобильной для потребителя транспортных услуг.

Приходится отметить, что транспортная инфраструктура нашей страны далеко не в полной мере отвечает современным запросам экономки и государственного строительства. Качество дорог многих транспортных магистралей, уровень технологического оснащения общественного транспорта, авиапарка, речных и морских судов оставляет желать лучшего. В этой связи только лишь правовые меры, а также разрешительная и страховая деятельность в сфере работы транспорта не дадут должного положительного результата в деле обеспечения транспортной безопасности. Учитывая опыт управления транспортом и транспортной инфраструктурой за рубежом, в нашей стране необходимо создать единый орган управления транспортом, отказаться от такой формы федерального органа исполнительной власти в сфере управления транспортом, как федеральная служба и федеральное агентство, а их полномочия передать Министерству транспорта Российской Федерации.

Весьма положительно - в некоторых зарубежных странах - себя зарекомендовали дорожные советы созданные при местных органах власти. В компетенции этих советов сосредоточены весьма существенные административные и финансовые полномочия в сфере дорожного строительства и поддержания дорожной инфраструктуры.

Также перспективным видится использование полиции в обеспечении транспортной безопасности. В целом ряде зарубежных стран наблюдается тенденция

государствах // Полицейская деятельность. - 2013. № 3. - C. 276 . 
DOI: $10.7256 / 1811-9018.2014 .8 .11549$

При цитировании этой статьи сноска на доі обязательна

\section{Право и политика $8(176) \cdot 2014$}

отказа от использования негосударственных структур, занимающихся вопросами обеспечения безопасности, в частности, вопросами обеспечения авиационной безопасности. Представляется необходимым пересмотреть роль и значение российской полиции в вопросах обеспечения авиационной безопасности, а также безопасности на речном и морском транспорте.

Представляется также необходимым отметить, что в сфере деятельности по повышению эффективности действующего законодательства, следует идти по пути более детального определения составов административных правонарушений, объектом посягательства которых являются разнообразные общественные отношения в сфере обеспечения транспортной безопасности. Весьма перспективным видится совершенствование правовых и организационных основ взаимодействия различных зарубежных государств и международных транспортных организаций с уполномоченными органами исполнительной власти Российской Федерации в сфере обеспечения транспортной безопасности, а также гармонизация российского законодательства в соответствующей сфере с законодательством зарубежных государств, которым удалось добиться высокого уровня транспортной безопасности. Несмотря на важность технической составляющей в вопросах обеспечения безопасности на объектах транспорта и транспортной инфраструктуры, правовое регулирование соответствующих отношений должно иметь определяющий характер 5 .

Проблемы обеспечения транспортной безопасности имеют межгосударственное значение, различные виды транспорта ежедневно пересекают множество границ различных государств. Поэтому для обеспечения безопасности функционирования авиационного и морского транспорта созданы специализированные международные организации, которые призваны унифицировать основные требования, касающиеся безопасности пассажиров, охраны окружающей среды при эксплуатации различных видов транспорта. Для этих целей принимается целый ряд международных документов, направленных на защиту, в частности, авиационного и морского транспорта от актов незаконного вмешательства в его деятельность и т.д.

Нормы международного транспортного права весьма органично вписаны в механизм административно-правового регулирования транспортной безопасности. Например, этими нормами устанавлива-

\footnotetext{
${ }^{5}$ См.: Костенников М.В., Трофимов О.Е. Правовое регулирование транспортной безопасности и роль полиции в ее обеспечении // Полицейская деятельность. - 2013 - № 4. - С. 402.
}

ются различного рода административные процедуры и регламенты эксплуатации авиационного транспорта, определяется комплекс запретов и ограничений при использовании морского транспорта, определяются стандарты при закреплении административно-правового статуса потребителей транспортных услуг и т.д. Несмотря на важное значение норм международного права при регулировании отношений связанных с обеспечением транспортной безопасности, все же определяющим в этом вопросе является российское транспортное законодательство, нормы которого касаются как регулятивных, так и охранительных отношений в соответствующей сфере. Так, нормами административного права определяется оценка уязвимости объектов транспортной инфраструктуры и транспортных средств, процедура аккредитации специализированных организаций в области обеспечения транспортной безопасности. Также нормами административного права определяются требования по обеспечению транспортной безопасности: перечень ограничений при приеме на работу, непосредственно связанную с обеспечением транспортной безопасности и др.

Важным институтом в деле обеспечения транспортной безопасности является лицензирование отдельных видов деятельности в области транспортной деятельности. Рассматриваемый институт вносит весьма существенный вклад в дело обеспечения транспортной безопасности, в этой связи предложения об отмене лицензирования и замене его процедурой страхования неадекватны действительности. На это могут указывать, в частности, такие цифровые данные, количество происшествий на автомобильном транспорте в 2012 г. в целом увеличилось на $10 \%$, а для лицензируемого автотранспорта оно сократилось на 4,3\% ${ }^{6}$.

Исходя из вышеизложенного, представляется возможным отметить, что основными направлениями деятельности федеральных органов исполнительной власти в сфере обеспечения транспортной безопасности является разрешительная, контрольная, а также юрисдикционная деятельность. В этой связи в Федеральном законе от 9 февраля 2007 г. «О транспортной безопасности» 7 необходимо поместить раздел о лицензировании деятельности в области транспорта, а также контроле в области обеспечения транспортной безопасности. Соответствующие направления деятельности должны находиться в предмете регулирования обозначенного федерального закона.

\footnotetext{
${ }^{6} \mathrm{http}: / / w w w . m i n t r a n s . r u /($ (дата обращения 18.03.2013).

${ }^{7}$ Собрание законодательства РФ. - 2007. - № 7. - Ст. 837.
} 
Кроме того, в целях более эффективного использования потенциала административной ответственности в сфере обеспечения транспортной безопасности, необходимо более дифференцированно подойти к формулированию диспозиций составов соответствующих административных правонарушений, объектом посягательства которых является транспортный комплекс нашей страны.

Реализация норм административного права в деятельности федеральных органов исполнительной власти по обеспечению безопасности на объектах транспорта и транспортной инфраструктуры порождает целый ряд правоотношений. Правоотношения, которые возникают в сфере обеспечения безопасности на объектах транспорта и транспортной инфраструктуры имеют определенные особенности, которые обусловлены основаниями их возникновения. Кроме того, обязательным участником соответствующих отношений является федеральный орган исполнительной власти, в компетенции которого находятся вопросы обеспечения безопасности на транспорте или специализированная организация, которой такое право специально предоставлено.

Следует также отметить, что проблема обеспечения транспортной безопасности - эта проблема, которую должно решать не только государство. Соответствующие вопросы напрямую касаются и транспортных предприятий и иных хозяйствующих субъектов, чья деятельность прямо или косвенно связана с работой транспорта и функционированием сопутствующей ему инфраструктуры. Правоотношения, возникающие в связи с обеспечением транспортной безопасности - это правоотношения не только вертикального, но и горизонтального характера. Связано это с тем, что проблемы транспортной безопасности невозможно решить только одному федеральному органу исполнительной власти, даже если его наделить исчерпывающим комплексом прав в соответствующей сфере. Обозначенную проблему в пределах своей компетенции должны решать и правоохранительные органы и органы государственной власти субъектов Российской Федерации, а также и органы местного самоуправления.

В условиях децентрализации управления транспортным комплексом, а также коммерциализации отношений в транспортном комплексе нашей страны, исключительно административными методами управления добиться максимального результата в деле обеспечения безопасности на объектах транспорта и транспортной инфраструктуры весьма затруднитель- но. В этой связи в решении обозначенной проблемы должны быть использованы такие методы управления, как координация и взаимодействие, а также комплекс стимулирующих средств, установленных для тех хозяйствующих субъектов, которые уделяют особое внимание вопросу обеспечения безопасности при эксплуатации соответствующего вида транспорта ${ }^{8}$.

Правоприменительные акты имеют весьма принципиальное значение для деятельности федеральных органов исполнительной власти по обеспечению безопасности на объектах транспорта и транспортной инфраструктуры. Обусловлено это тем, что сам процесс правоприменения носит властный характер, в связи с чем правоприменителем в соответствующих отношениях выступает уполномоченный в сфере обеспечения транспортной безопасности федеральный орган исполнительной власти или его должностное лицо.

Безопасность на объектах транспорта и транспортной инфраструктуры не существует сама по себе, это состояние достигается посредством вынесения и реализации самых различных правоприменительных актов, которые разрешают или запрещают какую-либо деятельность в сфере функционирования транспорта. Так, для осуществления деятельности по перевозки людей, опасных грузов различными видами транспорта, необходимо получение лицензии или иного разрешения. Основанием для вынесения запретительных актов является неудовлетворительное состояние транспортного средства, наличие высоких рисков транспортной безопасности при его эксплуатации и др. Определенное значение имеют предупредительные, пресекательные, а также юрисдикционные акты, которые выносятся Федеральной службой по надзору в сфере транспорта. Так, в интересах обеспечения транспортной безопасности только в апреле 2013 г. соответствующей службой было проведено 2411 инспекторских проверки, в ходе которых было выявлено 5446 нарушений транспортного законодательства, за нарушение которого к административной ответственности привлечены 2298 должностных и юридических лиц, 618 дел об административных правонарушениях направлены на рассмотрение в суды, а общая сумма наложенных штрафов за обозначенный период составила 7,7 млн руб. Полученные результаты стали возможны только вследствие своевременного вынесения актов применения норм административного права. В этой

\footnotetext{
${ }^{8}$ См.: Трофимов О.Е., Мотин В.В. Проблемы обеспечения безопасности на водном транспорте // Административное и муниципальное право. - 2013. - № 6. - С. 607.
} 
DOI: $10.7256 / 1811-9018.2014 .8 .11549$

При цитировании этой статьи сноска на доі обязательна

\section{Право и политика $8(176) \cdot 2014$}

связи в вопросах обеспечения безопасности на объектах транспорта и транспортной инфраструктуры, принципиальное значение должно придаваться составляемым документам, поскольку от этого, в конечном итоге зависит весь процесс обеспечения транспортной безопасности 9 .

С учетом высокого уровня террористической угрозы при эксплуатации воздушного и водного транспорта обоснована необходимость повышения роли транспортной полиции (вплоть до формирования специальных досмотровых групп состоящих исключительно из сотрудников полиции) при осуществлении досмотра пассажиров, багажа, грузов, а также сосредоточение системы управления безопасностью в аэропортах, морских портах, автовокзалах в управлениях МВД России на транспорте. С целью унификации требований в области обеспечения безопасности на различных видах транспорта, в частности, при применении мер административного воздействия, имеет место объективная необходимость принятия Транспортного кодекса Российской Федерации. В современных условиях развития транспорта его различные виды могут функционировать только во взаимодействии друг с другом. Транспортный кодекс должен стать связующим актом, призванным регламентировать режим функционирования различных видов транспорта. Принятие такого закона даст возможность повысить уровень взаимодействия всех элементов транспортной инфраструктуры, а также более эффективно обеспечивать транспортную безопасность. В концептуальном плане данный кодекс должен состоять из общей части, особенной и специальной ${ }^{10}$.

Для обеспечения безопасности пассажиров, а также перевозимых грузов, в Главу 11 КоАП России следует добавить статью, предусматривающую ответственность хозяйствующих субъектов за деятельность в сфере транспорта без лицензии или иного специального разрешения. Так же целесообразно расширить диспозицию ст. 11.15.1 КоАП России «Неисполнение требований по обеспечению транспортной безопасности» предписанием, предусматривающим ответственность за неосуществление оценки уязвимости объектов транспортной инфраструктуры и транспортных средств от актов незаконного вмешательства.

\footnotetext{
${ }^{9}$ См.: Мотин В.В. Проблемы обеспечения транспортной безопасности в условиях развития информационных технологий // Административное и муниципальное право. - 2012. - № 9. - С. 44.

${ }^{10}$ См.: Костенников М.В., Трофимов О.Е. Правовые и организационные проблемы обеспечения транспортной безопасности в деятельности органов исполнительной власти публикована // Полицейская деятельность. - 2013. - № 6. - С. 402.
}

В целях эффективного противодействия актам незаконного вмешательству в деятельность экипажа воздушного, морского или речного судна, а также пресечение административных правонарушений на бортах соответствующих транспортных средств, необходимо наделить командира воздушного судна и капитана корабля юрисдикционными полномочиями. В частности, этим должностным лицам необходимо предоставить право составлять протоколы об административных правонарушениях, если они совершены на борту воздушного, морского или речного, а также предоставить им право административного задержания соответствующих нарушителей. Такие полномочия необходимо закрепить в Главе 23 КоАП РФ. С учетом большой опасности административных правонарушений, совершаемых во время эксплуатации воздушного, водного и железнодорожного транспорта, было бы целесообразно дополнить ст. 4.3 КоАП России «Обстоятельства, отягчающие административную ответственность» пунктом «совершение административного правонарушения при эксплуатации пассажирского транспорта, если эти действия угрожают безопасности движения или пассажирам». Помимо этого представляется необходимым дополнить Главу 11 КоАП России статьей 11.9.1, предусматривающей ответственность в виде дисквалификации за управление воздушным и железнодорожным транспортом лицом, находящимся в состоянии опьянения.

Таковы общие положения, которые могут быть использованы для повышения эффективности обеспечения транспортной безопасности и защиты прав граждан в сфере функционирования транспортного комплекса нашей страны.

\section{Библиография:}

1. Куракин А.В., Трофимов О.Е. Административноправовое регулирование обеспечения безопасности авиации и объектов авиационной инфра-структуры в зарубежных государствах // Полицейская деятельность. - 2013. - № 3.

2. Костенников М.В., Трофимов О.Е. Правовое регулирование транспортной безопасности и роль полиции в ее обеспечении // Полицейская деятельность. - 2013 - № 4.

3. Костенников М.В., Трофимов О.Е.. Правовые и организационные проблемы обеспечения транспортной безопасности в деятельности органов исполнительной власти // Полицейская деятельность. -2013 . - № 6 . 
4. Костенников М.В., Куракин А.В. Актуальные проблемы административного права. - М., 2013.

5. 5. Мотин В.В. Проблемы обеспечения транспортной безопасности в условиях развития информационных технологий // Административное и муниципальное право. - 2012. - № 9.

6. Трофимов О.Е., Мотин В.В. Проблемы обеспечения безопасности на водном транспорте // Административное и муниципальное право. 2013. - № 6 .

7. Соломатина Е.А. Правовое регулирование деятельности полиции в зарубежных странах // NB: Российское полицейское право. - 2013. - 3. - С. 104118. DOI: $10.7256 / 2306-4218.2013 .3 .8916$. URL: http://www.e-notabene.ru/pm/article_8916.html

8. Мотин В.В., Трофимов О.Е. Проблемы обеспечения безопасности на водном транспорте // NB: Административное право и практика администрирования. - 2013. - 12. - C. 51-65. DOI: 10.7256/23069945.2013.12.10874. URL: http://www.e-notabene.ru/ al/article_10874.html

9. Куракин А.В. Компетенция полиции в сфере peализации законодательства об административных правонарушениях // NB: Административное право и практика администрирования. - 2013. - 4. С. 28-48. DOI: 10.7256/2306-9945.2013.4.8841. URL: http://www.e-notabene.ru/al/article_8841.html

10. Овчинников Н.А. К вопросу о понятии законности как одного из направлений противодействия коррупции в системе Министерства внутренних дел России // NB: Российское полицейское право. - 2013. - 1. - C. 84-98. DOI: 10.7256/23064218.2013.1.764. URL: http://www.e-notabene.ru/pm/ article_764.html

11. Шульц В. Л., Кульба В. В., Шелков А. Б., Чернов И. В. Методология управления техногенной безопасностью объектов инфраструктуры железнодорожного транспорта на основе индикаторного подхода // Тренды и управление. - 2013. - № 3. - С. 104-107. DOI: 10.7256/2307-9118.2013.3.7859.

12. Ерпылева Н.Ю., Максимов Д.М.. Правовое регулирование международных комбинированных перевозок грузов, пассажиров и багажа // Международное право и международные организации / International Law and International Organizations. - 2013. - № 4. - C. 104-107. DOI: 10.7256/2226-6305.2013.4.10356.

13. Ерпылева Н.Ю., Максимов Д.М.. Унификация правового регулирования международных речных перевозок грузов, пассажиров и багажа // Право и политика. - 2013. - № 10. - C. 104-107. DOI: 10.7256/1811-9018.2013.10.9193.

14. А.М. Скрынник. Мониторинг обеспечения транспортной безопасности в России // Право и политика. - 2013. - № 5. - С. 104-107. DOI: 10.7256/18119018.2013.05.9.

15. Н. Ю. Ерпылева, Д. М. Максимов. Правовое регулирование международных железнодорожных перевозок // Международное право и международные организации / International Law and International Organizations. - 2012. - № 3. - C. 104-107.

16. И. В. Федякин. К вопросу об использовании зарубежного опыта политики развития мегаполисов в современной России // Национальная безопасность / nota bene. - 2012. - № 4. - C. 104-107.

17. А. А. Паненков. Совершенствование правовой основы организации безопасности объектов использования атомной энергии и транспорта в 2011 году // Национальная безопасность / nota bene. - 2012. - № 2. - C. 104-107.

18. А. М. Скрынник. К вопросу о безопасности в области торгового мореплавания Российской Федерации // Национальная безопасность / nota bene. - 2011. - № 6. - C. 104-107.

19. А. С. Касаткина. Правовые основы регулирования международных пассажирских перевозок // Право и политика. - 2012. - № 3. - С. 104-107

\section{References (transliteration):}

1. Kurakin A.V., Trofimov O.E. Administrativnopravovoe regulirovanie obespecheniya bezopasnosti aviatsii i ob"ektov aviatsionnoi infrastruktury v zarubezhnykh gosudarstvakh // Politseiskaya deyatel'nost'. - 2013. - № 3 .

2. Kostennikov M.V., Trofimov O.E. Pravovoe regulirovanie transportnoi bezopasnosti i rol' politsii v ee obespechenii // Politseiskaya deyatel'nost'. - 2013 - № 4.

3. Kostennikov M.V., Trofimov O.E.. Pravovye i organizatsionnye problemy obespecheniya transportnoi bezopasnosti $\mathrm{v}$ deyatel'nosti organov ispolnitel'noi vlasti // Politseiskaya deyatel'nost'. - 2013. - № 6.

4. Kostennikov M.V., Kurakin A.V. Aktual'nye problemy administra-tivnogo prava. - M., 2013.

5. Motin V.V. Problemy obespecheniya transportnoi bezopasnosti v us-loviyakh razvitiya informatsionnykh tekhnologii // Administrativnoe i munitsipal'noe pravo. - 2012. - № 9 . 
DOI: $10.7256 / 1811-9018.2014 .8 .11549$

При цитировании этой статьи сноска на dоі обязательна

\section{Право и политика $8(176) \cdot 2014$}

6. Trofimov O.E., Motin V.V. Problemy obespecheniya bezopasnosti na vodnom transporte // Administrativnoe i munitsipal'noe pravo. - 2013. - № 6.

7. Solomatina E.A. Pravovoe regulirovanie deyatel'nosti politsii v zarubezhnykh stranakh // NB: Rossiiskoe politseiskoe pravo. - 2013. - 3. - C. 104-118. DOI: 10.7256/2306-4218.2013.3.8916. URL: http://www.enotabene.ru/pm/article_8916.html

8. Motin V.V., Trofimov O.E. Problemy obespecheniya bezopasnosti na vodnom transporte // NB: Administrativnoe pravo i praktika administrirovaniya. - 2013. - 12. - C. 51-65. DOI: 10.7256/23069945.2013.12.10874. URL: http://www.e-notabene.ru/ al/article_10874.html

9. Kurakin A.V. Kompetentsiya politsii v sfere realizatsii zakonodatel'stva ob administrativnykh pravonarusheniyakh // NB: Administrativnoe pravo i praktika administrirovaniya. - 2013. - 4. - C. 28-48. DOI: 10.7256/2306-9945.2013.4.8841. URL: http://www.enotabene.ru/al/article_8841.html

10. Ovchinnikov N.A. K voprosu o ponyatii zakonnosti kak odnogo iz napravlenii protivodeistviya korruptsii v sisteme Ministerstva vnutrennikh del Rossii // NB: Rossiiskoe politseiskoe pravo. - 2013. - 1. - C. 8498. DOI: 10.7256/2306-4218.2013.1.764. URL: http:// www.e-notabene.ru/pm/article_764.html

11. Shul'ts V. L., Kul'ba V. V., Shelkov A. B., Chernov I. V.. Metodologiya upravleniya tekhnogennoi bezopasnost'yu ob'ektov infrastruktury zheleznodorozhnogo transporta na osnove indikatornogo podkhoda // Trendy i upravlenie. - 2013. - № 3. - S. 104-107. DOI: 10.7256/2307-9118.2013.3.7859.
12. Erpyleva N.Yu., Maksimov D.M.. Pravovoe regulirovanie mezhdunarodnykh kombinirovannykh perevozok gruzov, passazhirov i bagazha // Mezhdunarodnoe pravo i mezhdunarodnye organizatsii / International Law and International Organizations. - 2013. - № 4. - S. 104-107. DOI: 10.7256/22266305.2013.4.10356.

13. Erpyleva N.Yu., Maksimov D.M.. Unifikatsiya pravovogo regulirovaniya mezhdunarodnykh rechnykh perevozok gruzov, passazhirov i bagazha // Pravo i politika. - 2013. - № 10. - S. 104-107. DOI: 10.7256/18119018.2013.10.9193.

14. A.M. Skrynnik. Monitoring obespecheniya transportnoi bezopasnosti v Rossii // Pravo i politika. - 2013. - № 5. - S. 104-107. DOI: 10.7256/18119018.2013.05.9.

15. N. Yu. Erpyleva, D. M. Maksimov. Pravovoe regulirovanie mezhdunarodnykh zheleznodorozhnykh perevozok // Mezhdunarodnoe pravo i mezhdunarodnye organizatsii / International Law and International Organizations. - 2012. - № 3. - S. 104-107.

16. I. V. Fedyakin. K voprosu ob ispol'zovanii zarubezhnogo opyta politiki razvitiya megapolisov v sovremennoi Rossii // Natsional'naya bezopasnost' / nota bene. - 2012. - № 4. - S. 104-107.

17. A. M. Skrynnik. K voprosu o bezopasnosti v oblasti torgovogo moreplavaniya Rossiiskoi Federatsii // Natsional'naya bezopasnost' / nota bene. - 2011. № 6. - S. 104-107.

18. A. S. Kasatkina. Pravovye osnovy regulirovaniya mezhdunarodnykh passazhirskikh perevozok // Pravo i politika. - 2012. - № 3. - S. 104-107 